\title{
Techniques for Preparation Geological Samples for EBSD Analysis: An Example of Iron Oxide - Quartz Aggregates
}

\author{
G. Alvares*, L. Lagoeiro** \\ * Department of Metallurgy, Federal University of Ouro Preto, MG, 35400-000, Brazil. \\ ** Department of Geology, Federal University of Ouro Preto, MG, 35400-000, Brazil.
}

Geological samples, from Quadrilátero Ferrífero, Brazil, were prepared for SEM and EBSD analysis. Thin sections and mounted blocks of Polycrystalline Hematite aggregates, pure Quartz and a Hematite/Quartz compounds were used in this work, aiming to reach a successful polishment process, which would be able to produce high quality samples for compositional and textural analysis. The polishing process was the same for all minerals, except for the time used, that ranged accordingly to the mineral hardness.

Polycrystalline Hematite aggregates were prepared through a mechanically polishing process [1] with diamond pastes of $9,3,1 \mu \mathrm{m}$ and monocrystalline diamond suspension of 0,25 and $0,10 \mu \mathrm{m}$ for 25 minutes. Then, they received a lapping procedure with an alkaline solution of colloidal silica (25nm) for 2-4 hours. Pure Quartz samples received a mechanically polishing process with diamond pastes of 9,3,1 $\mu \mathrm{m}$ and monocrystalline diamond suspension of 0,25 and $0,10 \mu \mathrm{m}$ for 1 hour; and it's lapping procedure with colloidal silica $(25 \mathrm{~nm})$ ran for 4-8 hours. Hematite/Quartz compounds received a mechanically polishing process with diamond pastes and monocrystalline diamond suspension as in Hematite aggregates, and the lapping procedure with colloidal silica was the same in pure Quartz aggregates. The polisher was set at $25 \mathrm{rpm}$ and $5 \mathrm{lb}$ for all samples.

The results show an outstanding polishing quality for pure hematite aggregates, with a complete flat surface and a good pattern quality index, approximately 140, in a band contrast scale (Figure 1). The pure quartz aggregates ended up with a non-complete flat surface, which might deteriorate the pattern quality index, with gains between 90 and 115(figure 2). In the compound Hematite/Quartz the polishing procedure was not able to flatten the surface evenly. When analyzing the minerals, the map shows a slight decrease in a Hematite pattern quality index and a considerable decrease in the patterns for the Pure Quartz aggregates.

In conclusion, the polishing process applied to Hematite is satisfactory. However, for the pure quartz aggregates it needs to be improved, perhaps increasing the time for a mechanical polishing as well as for a final colloidal silica lapping. The same procedure should also be applied to hematitequartz aggregates. But certain cares must be taken. Quartz is the hardest phase. What would be an adequate polishing procedure for quartz might be too much for hematite, leading to an excessive grinding of the softer phases.

\section{References:}

[1] Fynn, G.W. and Powell, W.J.A. (1979) The cutting and polishing of electro-optic materials, 216 p. Adams Hilger, London. 

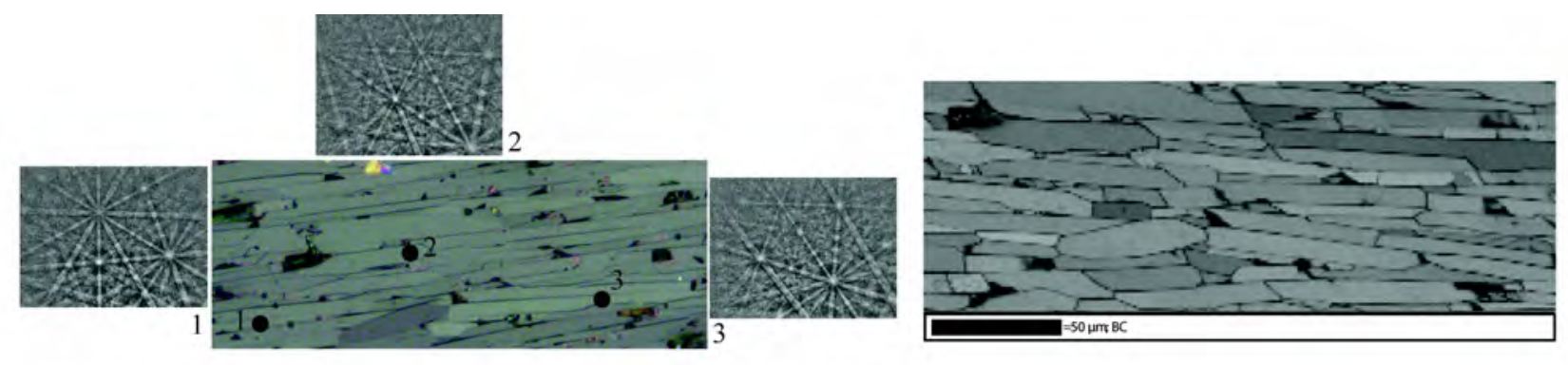

Figure 1: Hematite optical image (left) and Band Contrast map (right), and some grains in highlights showing the pattern quality.
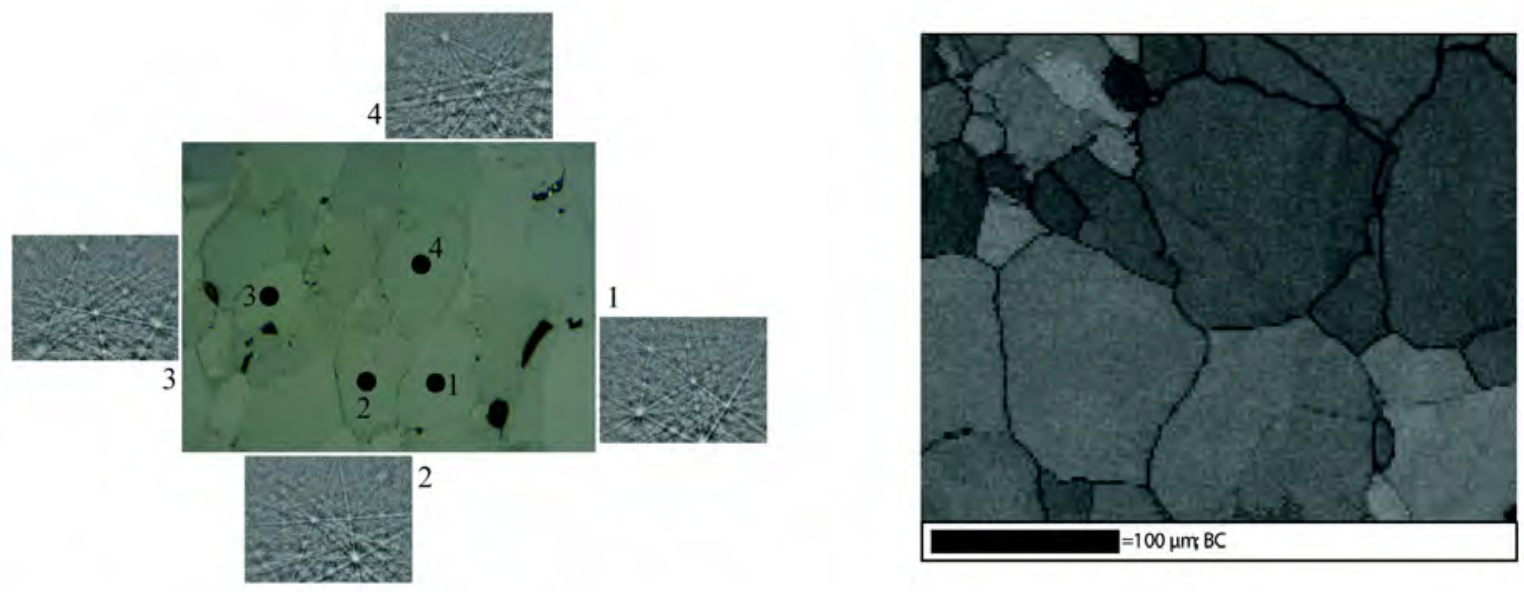

Figure 2: Quartz optical image (left) and Band Contrast map (right), and some grains in highlights showing the pattern quality.
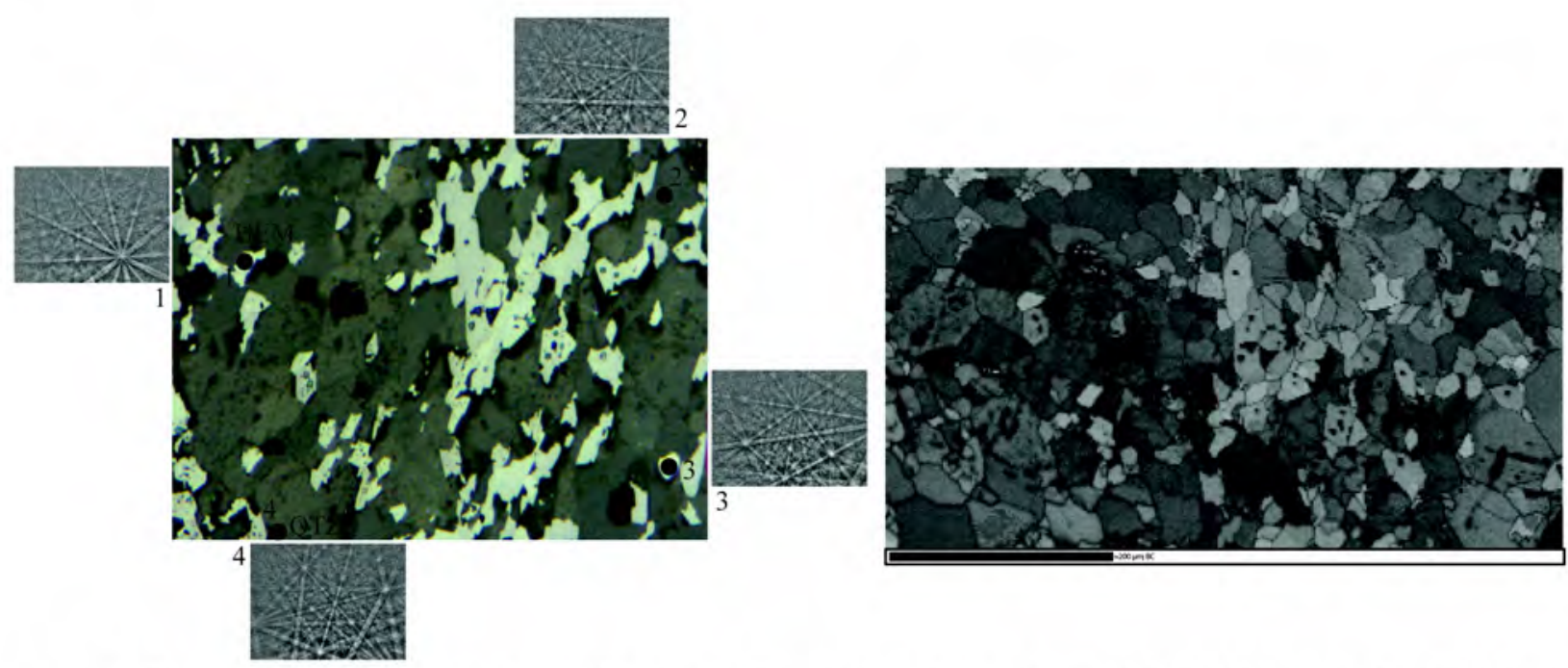

Figure 3: Hematite/Quartz compound optical image (left) and Band Contrast map (right), and some grains in highlights showing the pattern quality 